\title{
STUDIES
}

DOI: $10.2478 /$ atd-2018-0001

\section{Challenges and Curriculum Transformation in the Higher Education Sector in South Africa: A Case Study in WASH to Improve the Training of Pharmacists}

\author{
Roman Tandlich - Nosiphiwe P. Ngqwala-Aileen Boshoff-Phindile \\ Madikizela - C. Sunitha Srinivas - Desmond M. Pyle - \\ Rene Oosthuizen*
}

Received: March 5, 2018; received in revised form: March 15, 2018; accepted: March 16, 2018

\begin{abstract}
:
Introduction: South Africa is a member state of the "BRICS" bloc (BRICS2017.org, 2017) and the G20 group of the 20 nations/economic blocs, which between them account for the majority of the world's trade and economic activity. It faces many developmental challenges which are mirrored in its higher education sector. In this article, the authors seek to provide an overview of the challenges that South African higher education faces in the achievement of the developmental goals of the country. The focus of this paper is a case study in WASH (water, sanitation and hygiene) to improve context-specific responses that trains pharmacists on knowledge and skills.

Methods: The study was performed as a combination of calculations and a literature review to obtain the background or current status of the higher education sector and developmental planning in South Africa. For this, data were extracted from the Statistics South Africa reports, relevant professional articles on South African higher education sector and results of postgraduate research. Workshop results which were obtained as a collaboration between a public and a private higher education institution and results of postgraduate research were used as the paradigm for transformation and decolonisation of the curriculum for a professional degree in South Africa.
\end{abstract}

\footnotetext{
"Roman Tandlich, Rhodes University, Faculty of Pharmacy, Grahamstown, South Africa; roman.tandlich@gmail.com

Nosiphiwe P. Ngqwala, Rhodes University, Faculty of Pharmacy, Grahamstown, South Africa; n.ngqwala@ru.ac.za

Aileen Boshoff, Rhodes University Biotechnology Innovation Centre, Grahamstown, South Africa; a.boshoff@ru.ac.za

Phindile Madikizela, Rhodes University, Faculty of Pharmacy, Grahamstown, South Africa; pyradim5@gmail.com

C. Sunitha Srinivas, Rhodes University, Faculty of Pharmacy, Grahamstown, South Africa; s.srinivas@ru.ac.za

Desmond M. Pyle, School of Disaster Management, Stenden South Africa, Port Alfred, South Africa; d.pyle@kingswoodcollege.com

Rene Oosthuizen, School of Disaster Management, Stenden South Africa, Port Alfred, South Africa; rene.oosthuizen@stenden.com
} 


\title{
Acta Educationis Generalis \\ volume 8,2018 , issue 1
}

\begin{abstract}
Results and discussion: Challenges exist in the South African tertiary education sector and the graduation rate currently stands at $65.1 \%$ of the target set by the National Development Plan. Around $58.1 \%$ of all students do not complete their university/post-secondary education, which could provide a partial explanation for the skills shortage in South Africa. Decolonisation and transformation of the tertiary education curriculum are major topics in the discourse on higher education in South Africa. The authors propose that one way to achieve this would be inclusion of research results and group activities in the area of water, sanitation and hygiene as a topic for possible and partial transformation of the Bachelor of Pharmacy curriculum.

Conclusions: The current article summarises some of topics and challenges that drive the current discourse, developmental and curriculum debate in higher education in South Africa. Student access and through put at tertiary institutions need to be improved and the curriculum needs to be transformed.
\end{abstract}

Key words: H2S test kit, lifelong learning, Bachelor of Pharmacy, university stakeholder interaction, sanitation.

\section{Introduction}

The total population of South Africa was estimated at 55908900 in 2016, with the annual rate of growth of $1.19-1.24 \%$ (Stats SA, 2016a, Tables 1 and 5). The country has reached a medium level of human development, as the human development index was equal to 0.666 in 2015 (UNHDI, 2016). South Africa has the most advanced economy on the African continent, but unemployment remains high and this is a source of major developmental and social challenges in the country (Keeton, 2014). The Gini coefficient/index for South Africa ranged from 63.0 to 64.8 between 2006 and 2011, making it the country with the highest inequality with respect to the population's income distribution in the world (WB, 2017a). Besides income, the inequality in South Africa has also been demonstrated by the fact that the majority of the population has not been achieving their educational potential (Keeton, 2014). Human capital and structure of spending on R\&D are challenges faced by the country (Blankley \& Booyens, 2010).

South Africa has a well-developed system for knowledge generation, science and technology. At the national level of government, there is a dedicated Ministry of Science and Technology which is responsible for the government's agenda in the field of scientific research and development in the country (DST, 2018). Execution of this agenda is then carried out by grant-making bodies such as the National Research Foundation of South Africa (NRF, 2018). Various sectors, such as water and sanitation, have further designated funding agencies such as the Water Research Commission (WRC, 2018). Technology development and research is run through a legislated system of state-funded institutions, such the Council for Scientific and Industrial Research (CSIR-Health, 2018), Human Sciences Research Council (HSRC, 2018) and similar organisations. Significant research and development takes place in the higher education sector. Innovation and launch of products into the market can be achieved using designated funding mechanisms, such as the Technology Innovation Agency (TIA, 2008-2018).

The structure of the system that drives science and technology, and research in South Africa is interlinked with the complexity of the world today. This complexity is a reflection of the fact that the world is changing at an exponential rate, and this has highlighted the importance of lifelong learning (Visser \& Berg, 1999). Information 


\section{Acta Educationis Generalis \\ volume 8, 2018, issue 1}

literacy is key to the realization of lifelong learning activities and those who actively learn all the time are able to access information easily (Demirel, 2009). In the information age, learners need to interpret and use scientific data to produce new data and solve problems. Important aims of lifelong learners are to improve the quality of their lives by striving to reach their greatest potential and adjusting to changes. Gaining correct and proficient learning experiences are important for personal growth. A fundamental component of lifelong learning requires that educators themselves be lifelong learners (Demirel, 2009). Many educators work in universities and vocational/technology sectors in South Africa and are involved in research and development of new knowledge. Therefore, research generated in the country provide another dimension in lifelong learning and knowledge society.

In the 21 st century, tertiary education plays various societal roles and it helps to provide solutions to challenges in the ever-changing landscape of transforming countries (Janeček, 2006). Knowledge society or knowledge economy encompasses settings where knowledge generated or adopted in a particular country is used as a "tool to derive economic benefits" (Vadra, 2017), for the good of the said country and its population. Realisation of a knowledge economy in a particular country indicates the stage of human development where high value-added products and services are major sources of the overall economic activity, employment and personal income of citizens and tax revenue for the government (Chen \& Dahlman, 2005). Higher education in a knowledge economy can also be used as a tool to decrease unemployment (Hužovičová \& Jakúbek, 2014). To achieve the development of a knowledge society, tertiary education needs to contribute to fulfilling of a "nation's economic and social goals", and to be the source of "innovation and skills development" (OECD, 2008-2017). Therefore, tertiary education plays and will continue to play a key role in accomplishing the development of a knowledge economy in South Africa. In this article, the authors seek to provide an overview of the challenges that the South African higher education faces in the achievement of the developmental goals of the country.

South Africa is a water scarce country and is ranked 143rd in the world in terms of annual precipitation levels (as summarised in Index Mundi, undated). Part of the National Development Plan is to decrease mortality among children under 5 years to 30 per 1000 live births by 2030 (SADOH, 2015). In order to achieve these goals, South Africa needs to reduce the disease burden and improve health. Numerous communicable diseases are related to water, sanitation and hygiene (collectively termed WASH) in the country. Factors influencing the WASH situation in South Africa will include access to improved drinking water and improved sanitation facilities. As pharmacists are part of the health workforce in South Africa, the Bachelor of Pharmacy curriculum must include coverage of WASH and its relation to disease spread/burden in the country. At Rhodes University, many Bachelor of Pharmacy students come from areas where water and sanitation service delivery are a problem. Therefore, challenges associated with WASH are familiar to the student body. WASH and water supply/public health issues water provide a platform to connect the students to a professional-health degree curriculum and initiate potential transformation of the curriculum. A case study in WASH is provided as evidence that changes to the curriculum in response to societal challenges can improve the training of pharmacists. 


\section{Acta Educationis Generalis \\ volume 8, 2018, issue 1}

\section{Methodology}

The authors used a combination of calculations and a literature review to obtain the background or current status of the higher education sector and developmental planning in South Africa. For this, data were extracted from the Statistics South Africa reports, relevant professional articles on South African higher education sector and results of postgraduate research. Cooperation between public and private higher education institutions provides another angle for the transformation of the curriculum. Results of the workshop run at Stenden South Africa is used as an example. The workshop was run with the first-year students enrolled in the Bachelor of Business Administration in Disaster Management degree at the School of Disaster Management at Stenden South Africa in October 2014. The first part was a lecture-based introduction to disaster management risks and dimensions of water, sanitation and hygiene (WASH). Disaster risk was explained in terms of the infectious dose of particular pathogens, the types of pathogens that can be encountered in faecally-contaminated water resources; and how sanitation wastes from improved sanitation, such as the ventilated improved pit latrines, can pose risks to the public health and disaster risk management in South Africa.

In the second part of the workshop, the students were split into small groups of 3 to 4 students and asked to design an information material/checklist for the disaster management professionals to be able to deal with WASH-related aspects of disaster situations and public health. The principle of the disaster management cycle was used as the paradigm and the ventilated improved pit latrines were used as a model. The student groups worked independently for about three hours. Each group was assisted by postgraduate students from the Faculty of Pharmacy at Rhodes University, who were studying towards Master of Science in Pharmacy and Doctor of Philosophy in Pharmacy. Their theses were focused on topics related to WASH. After the three-hour breakaway sessions, each group of the first-year disaster management students presented their version of the leaflet to the entire class at the end of the workshop. The final version of this tool/checklist was summarised as the overlap between the individual student group's tools and was compiled by the authors (see Appendix). The final leaflet was given to the students who participated in the workshop. The authors applied for ethical clearance for the involvement of human subjects in research to the Faculty of Pharmacy Ethics Committee and the approval was granted under the tracking number PHARM 2014-36.

\section{Results and discussion}

\subsection{Developmental planning and tertiary education in South Africa}

The focus on a knowledge economy is indirectly mentioned in South Africa's National Development Plan 2030 (NDP; NPC, 2013). Chapter 1 contains a clear commitment/understanding by the national government that places education and skills development at the core of development in South Africa, reduction of unemployment in the country and the achievement of a more equitable society (NPC, 2013, Chapter 1). Reduction of poverty and the elimination of obstacles to tertiary education and vocational training play a crucial role in this context (NPC, 2013, Chapter 1). One of the targets in this regard is to increase the proportion of the South African population that is enrolled and educated at the technical and vocational colleges (TVET colleges) to $25 \%$ of the population by 2030 (NPC, 2013, Chapter 1). From these enrolled students, 75\% should graduate (NPC, 2013, Chapter 1). Financial assistance should be provided to the 


\section{Acta Educationis Generalis \\ volume 8, 2018, issue 1}

students in the TVET colleges to cover all the costs associated with their studies (NPC, 2013, Chapter 1).

The knowledge economy status of a given society/country can be assessed using the KAM methodology of the World Bank. The KAM contains four "pillars" that must be in place for the "successful transition of a country to a knowledge economy" (Chen \& Dahlman, 2005). The individual pillars include the "educated and skilled workforce", efficient framework for creation and dissemination of knowledge, highly developed ICT infrastructure and sufficient R\&D infrastructure - government and private, industrial and academic, etc. (Chen \& Dahlman, 2005). This is at the core of the suggested improvements to "education, training and innovation" in South Africa (NPC, 2013, Chapter 9). Improvement in education and skills levels, as well as R\&D, must be the focus, along with meeting the health challenges facing South Africa (NPC, 2013, Chapter 9, p. 297). A sufficient pool of healthcare professionals and researchers is necessary to achieve these goals (NPC, 2013, Chapter 9, p. 297). Some data are provided below to assess the current status of achieving the NDP goals for tertiary education.

The words enrol and attend, as well as the related nouns/adjectives, will be considered synonymous in further text. Tertiary education and post-secondary education will also be considered mutually synonymous in the text below. The segment will represent the segment of the South African population aged 18 to 29. Finally, public university will represent any public university or public university of technology in South Africa. In 2016, between 7.5 and $34.9 \%$ of the segment was enrolled in post-secondary education (see Figure 3.3 on page 52 in Stats SA, 2017a). The authors calculated the average enrolment rate for this segment to be equal to $19.8 \%$. The calculation was based on equal weighting of enrolment rates for each year of age in the segment (see Figure 3.3 on page 52 in Stats SA, 2017a). Between 2002 and 2016, the percentage of the segment who attended public universities ranged from 4.0 to $4.5 \%$ (see Figure 11 on page 16 in Stats SA, 2017b). The percentage of the South African population 20 years of age or older that attained post-secondary education, i.e. graduated from a TVET college or a public university, was estimated at $14.0 \%$ in 2016 (see Figure 13 on page 18 in Stats SA, 2017b).

The student graduation rates from public universities can be calculated based on the data compiled by van Broekhuizen et al. (2016). Table 3.1 on page 18 of this publication contains the enrolment of the 2008 matric class who passed their final examination, i.e. the National Senior Certificate, into public universities. Data in column 3 indicate that the total number of first-time enrolments and/or delayed enrolment into public universities was equal to 112042 between 2009 and 2014 (van Broekhuizen et al., 2016). The total number of those students who graduated or graduated with a degree between 2009 and 2014 ranged from 38229 to 55721 (see columns 6 and 7 in Table 3.1 in van Broekhuizen et al., 2016). This includes students who completed a certificate course, national diploma or graduated with a bachelor's degree. Taking all this information into account, the undergraduate graduation rates from public universities (UGR) can be estimated using these data as calculated and shown in Equation (1) below.

$\operatorname{UGR}(\%)=\frac{46975}{\lceil 112042\rceil} \times 100=41.9 \%$

In Equation (1), the numerator represents the average number of students from the 2008 matric class who enrolled and graduated from a public university between 2009 and 


\section{Acta Educationis Generalis \\ volume 8, 2018, issue 1}

2014, i.e. the average of 33229 and 55 721. The denominator of Equation (1) represents the total number of 2008 matric class pupils who enrolled in a public university between 2009 and 2014. The result of the calculation in Equation (1) indicates that the UGR value was equal to $41.9 \%$ between 2009 and 2014. The total percentage of the South African population who have graduated from a public university between 2009 and 2014 (PPUD) can be estimated using Equation (2).

PPUD $(\%)=0.419 \times 0.0425 \times 100=1.8 \%$

In Equation (2), the number 0.0425 is the dimensionless fraction of the South African population who were enrolled in a public university between 2009 and 2014. It was assumed to be equal to the average of the attendance rates between 2002 and 2016 (see Figure 11 on page 16 in Stats SA, 2017b). As a result of the calculation in Equation (2), the PPUD value was calculated as equal to $1.8 \%$ between 2009 and 2014 . This estimate will be assumed to be equal to the PPUD value for 2016.

Taking the data from the previous several paragraphs into account, the following conclusions can be made about the current status of the achievement of the National Development Plan 2030 goals. The goal for enrolment of $25 \%$ of the population into TVET colleges (NPC, 2013, Chapter 1) has been partially achieved for selected age groups of enrolled students. However, the average rates are still below the target as indicated by the weighted average for the segment of the South African population, i.e. $19.8 \%$. With respect to the graduation rate for the TVET college-enrolled students, the following calculation can be made as shown in Equation (3).

$\operatorname{GTVET}(\%)=(14.0-1.8) /[25 \times 0.75] \times 100=65.1 \%$

In Equation (3), the numerator represents the percentage of the population which attained a TVET qualification and this parameter is calculated as the difference between the total percentage of the South African population segment, which is 20 years or older, and those that have attained a post-secondary qualification; and the percentage of the population which has attained a tertiary qualification from a public university. The denominator represents the NDP target. As it can be seen, $65.1 \%$ of the NDP target for TVET graduation has been achieved by 2016. The enrolment rates of eligible students/pupils in post-secondary education in South Africa are lower or comparable to other BRICS countries, with the exception of Russia, which ranged from 15 to $35 \%$ of the "university-aged population" (Carnoy et al., 2013, p. 37).

\subsection{Transformation of the South African higher education sector after 1994}

Prior to 1994, the South African higher education sector was not representative of the demographics of the country. Therefore, one of the main transformation goals, between 1994 and present day, has been to increase access and enrolment of Black South African students at the tertiary education institutions. This goal has largely been achieved as demonstrated by the fact that an estimated 766812 students were enrolled in public universities in 2016, with about two thirds being Black South Africans (see page 16 in Stats SA, 2017b). The "bachelor pass" data indicate the proportion of matriculants that qualify/are eligible for enrolment into public universities based on their matric results (van Broekhuizen et al., 2016, pp. i-viii). The "bachelor pass" data for the 2008 


\section{Acta Educationis Generalis \\ volume 8, 2018, issue 1}

matriculants and their enrolment in public universities between 2009 and 2014 showed that the following results. Approximately $63.2 \%$ of White South African students enrolled in a public university, compared to $71.2 \%$ of Black South African students (van Broekhuizen et al., 2016, pp. i-viii).

More recent data on post-secondary school education are available for the 17 - 24-yearold South Africans for 2016. For White South Africans, the attendance rates ranged from 6.8 to $55.2 \%$ in this academic year (see Figure 3.5 on page 54 in Stats SA, 2017a). At the same time, the enrolment rates for Black South Africans ranged from 7.9 to $33.8 \%$ in 2016 (see Figure 3.5 on page 54 in Stats SA, 2017a). The university drop-out rates ranged from 17 to $33 \%$ between 2009 and 2014, with the lowest percentage of White South African students and the highest of Black South Africans (van Broekhuizen et al., 2016, pp i-viii). Therefore, the available data used by the authors indicate that the transformation of the student body, in terms of access to black students, in the postsecondary education in South Africa has been achieved, but the statistics show that dropout rates still disproportionately affect the Black African students.

The estimated UGR of $41.9 \%$ of the enrolled students indicates that $58.1 \%$ of all enrolled students never finish the degrees they started, i.e. any types of university qualification which could be a bachelor's degree, national diploma or post-matric certification courses run at public universities. At least part of these types of qualifications will be skills driven, i.e. will be targeted to provide graduates with skills to work in specific industries. As a result, if more than half of the enrolled students drop out then this could provide a partial explanation for the shortages of skills in the South African R\&D and various industries. The fraction of the South African population with a university qualification was estimated at $1.8 \%$. This number is lower of comparable to the BRICS level, such as the data for Russia (OECD, 2015). Based on the above information, challenges remain in the South African higher education sector.

These challenges could have been among the triggers of the "fees-must-fall protests" by students at public university campuses across South Africa between 2015 (Luescher et al., 2017) and 2017 (News24.com, 2017). The contributing factors were recently analysed and proposed by Badat (2015, pp. 74-76). They include general underfunding of the public higher education sector by the South African government, declining government contribution as a relative percentage of the budgets of individual public universities and thus the need for annual tuition fee increases, insufficient financial assistance for students from poor and low-middle income backgrounds, limited resources for running of the foundation studies programmes at public universities and underspending by the government on higher education infrastructure (Badat, 2015, pp. 74-76). In summary, Badat's analysis points to financial challenges in the institutions of higher education in South Africa. However, there is a limit to the amount that can be spent on public funded universities due to national budget constraints.

Another trigger for the "fees-must-fall protests" could be the current discourse in the tertiary education sector in South Africa. This discourse has recently been re-focused on the notion of "decolonisation of the curricula and knowledge" taught at the public universities (Heleta, 2016). It has been argued that focus on colonial knowledge may result in a lack of development of the students" "analytical and critical skills" (Heleta, 2016). However, caution needs to be exercised in science-driven subjects and degrees as scientific knowledge is acquired through validated scientific methods; and curriculum 


\section{Acta Educationis Generalis \\ volume 8, 2018, issue 1}

transformation should include problem solving approaches to meet specific societal challenges in the South African context.

Curriculum transformation of higher education will be subject-specific and must be carefully carried out to comply with the SAQA requirements, especially for professional degrees (SAQA, 2015-2018). Adhering to the fundamental and applied knowledge that students have to master a particular degree cannot be compromised. Therefore, after understanding the regulatory framework in which a particular degree has been accredited, the next step is to identify and clearly define the learning outcomes, followed by the identification of appropriate teaching and learning activities to support the learning process and finding appropriate assessment tasks (Jůvová, 2017). Next, these outcomes and methods can be examined in the context of the students' experiences and perceptions about the tertiary education environment. Students should be able to relate to the societal challenges and learn how science can support the society. Below is a potential paradigm for a professional university degree in South Africa.

\subsection{Bachelor of Pharmacy as a professional degree in South Africa}

Lifelong learning is active learning that takes place throughout a person's lifetime in both formal and informal contexts. It is not limited to university education, but rather includes all forms of learning. It is an essential concept in the thinking about education and training worldwide. The notion of lifelong learning is characterised by the desire to retain the development of knowledge and skills and also to maintain an interest in learning opportunities. A basic principle of lifelong learning is the continuous attainment and development of capabilities and aptitudes in formal, non-formal and informal ways during a person's lifespan (Steffens, 2015). The four pillars of lifelong learning can be summarized by Delors (1996) as learning to know, learning to do, learning to live together and learning to be a complete person. These are also relevant at tertiary education institutions.

Once at a tertiary institution, students are exposed to novel subject matter which builds on the foundation of previously acquired knowledge. Previously acquired knowledge comes from instruction at the secondary level of education and/or from instruction during lower university years. Through various educational activities, university students are guided and work towards achieving formal tertiary qualifications, i.e. meeting the requirements of the certificate course, national diploma or degree they are studying towards. In South Africa, all university degrees are accredited by the South African Qualifications Authority (SAQA, 2014). Professional degrees, such as qualifications in pharmacy, also have to conform to the standards set by professional bodies (SAPC, 2017a-c). After completion of these degrees, professionals need to register with professional bodies to be able to practice (SAPC, 2017a-c). One of the prerequisites for registration as a pharmacist in South Africa is the completion of the undergraduate degree of Bachelor of Pharmacy (B. Pharm.; SAPC, 2017a-c).

The B. Pharm. degree curriculum is at the interface of pharmacology, biochemistry, medicinal chemistry, microbiology, pharmacy practice and public health (SAPC, 2017). The B. Pharm. degree curriculum is at the interface of biochemistry, medicinal chemistry, microbiology, pharmacy practice and public health (e.g. Tandlich et al., 2013). The public health dimension is related to the challenges of South Africa's healthcare system (SADOH, 2015): the HIV/AIDS epidemic, non-communicable and communicable diseases; and injuries/trauma. The total expenditure on healthcare 


\section{Acta Educationis Generalis \\ volume 8, 2018, issue 1}

amounted to $8.5 \%$ of South Africa's gross domestic product in 2015 (SADOH, 2015), which is in line with the country's international commitments as part of the Abuja Declaration (e.g. WHO, 2011). The life expectancy at birth stood at 62 years in 2015 (WB, 2016a). To further improve the public health situation in South Africa, its country cooperation strategy with the World Health Organisation (WHO) for 2016-2020 outlines the need to "prevent disease, reduce disease burden and promote health"; and also to "improve human resources for health" (WHO, 2016, p. 2).

The provision of water and sanitation in South Africa is governed in the first instance by the Water Services Act no. 108 of 1997 (South African Government, 1997). Chapter 1 section 1 xvii of the act defines the water services as "water supply services and sanitation services" (South African Government, 1997). "Sanitation services" are defined in the Water Services Act as "the collection, removal, disposal or purification of human excreta, domestic waste-water, sewage and effluent resulting from the use of water for commercial purposes" (South African Government, 1997, Chapter 1 section $1 \mathrm{xvi})$. At the same time, the "water supply services" are defined as "the abstraction, conveyance, treatment and distribution of potable water, water intended to be converted to potable water or water for commercial use but not water for industrial use" (South African Government, 1997, Chapter 1 section 1xxiv). Local government generally functions as a "water services authority", i.e. which is "any municipality, including a district or rural council as defined in the Local Government Transition Act, 1993 (Act No. 209 of 1993) and that is responsible for ensuring access to water services" (South African Government, 1997, Chapter 1 section 1xix).

These factors will play a critical role in the achievement of the public health goals of the National Development Plan, e.g. the decrease in the mortality among children under 5 years to 30 per 1000 live births by 2030 (see summary in Chapter 1, section 1.2.2 point 43, SADOH, 2015). The B. Pharm. curriculum should include knowledge of WASH and its influence on the spread of disease in the country. Water scarcity and problems with supply are on the border between human rights and science. Passions about the subject generally run high in South Africa, especially if infrastructure and supply are compromised. As such, WASH and health issues relating to water provide a platform to connect the students to a professional-health degree curriculum and initiate transformation of the curriculum.

This is further supported by WASH as an education topic and the related focus on citizenship in education (Hager, 2012). Active citizenship and its interlinking with higher education provide an ideal platform for transformation of the tertiary education curriculum. WASH as a topic has potential for ongoing, continuous and reflective learning. An emerging focus of lifelong learning is the health of society's citizens as this plays a role in self-governance and health improvement (Talati, 2014). Lifelong learning and reflective learning also entails an awareness of the environment and structures of society; and feedback between the two should be considered when formulating rational health strategies (Talati, 2014). WASH and a possible paradigm for the partial transformation of B. Pharm. curriculum is provided below.

\subsection{WASH background of South Africa}

According to data from the United Nations, a country is water-scarce if the renewable/available water volume per capita per year is below $1000 \mathrm{~m}^{3}$ (UN, 2014). Between 2002 and 2014, the annual water volume per capita decreased from 976.982 to 


\section{Acta Educationis Generalis \\ volume 8, 2018, issue 1}

$827.381 \mathrm{~m}^{3}$ in South Africa (WB, 2017b). The average annual precipitation has been reported to be around $495 \mathrm{~mm}$ in South Africa in 2014 (WB, 2017c). In that calendar year, the worldwide data for the total annual precipitation were recorded for 185 countries (as summarised in Index Mundi, undated). The highest annual precipitation was recorded in Colombia, namely $3240 \mathrm{~mm}$ per annum, while the lowest annual precipitation of $51 \mathrm{~mm}$ per annum was reported for Egypt (as summarised in Index Mundi, undated). South Africa was ranked 143rd in the world, i.e. therefore the annual precipitation in South Africa was probably below the global average in 2014.

Water scarcity of South Africa has recently been exacerbated by the 2015 El-Niñorelated drought. Major metropolitan areas have been running out of drinking water and might reach the so-called "day zero" when the municipal drinking water supply will be completely stopped. Since the onset of the El-Niño drought, the city of Cape Town has been implementing water restrictions or supply rationing. Level 6 water restrictions were implemented on 1st January 2018. Under these restrictions, each household in the metropolitan area of Cape Town is obliged to consume no more than 10500 litres of municipal drinking water per month, i.e. 87 litres/capita/day. A further cut to 50 litres/capita/day has since been implemented (The South African, 2018). All non-potable uses of municipal drinking water by households, such as lawn and garden irrigation, are strictly prohibited. Business users in the metropolitan areas must decrease their water consumption from municipal drinking water by $45 \%$ in comparison to the pre-2015 drought levels, while a $60 \%$ compulsory cut applies to all agricultural users. Similar water restrictions are in place in other parts of South Africa, e.g. the Nelson Mandela Metropolitan Municipality in the Eastern Cape Province.

The South African government has long been implementing strategies to help deal with water scarcity in the country (WRC, 2016). The combination of all these and other strategies helped the country achieve the Millennium Development Goal (MDG) 7C of access to improved drinking water. This can be demonstrated by the results of recent surveys which indicate that percentage of the South African households with access to improved drinking water ranged from 87.1 to $97.7 \%$ of the population and the access increased with increasing household income (quintile) in 2015 (Stats SA, 2016b, Figure 6.7 , p. 35). Investment of 1 USD into the provision of access to safe drinking water and the achievement of the MDG 7, has been estimated to result in approximately 4 USD in public health returns.

On the sanitation front, every 1 USD invested in achieving the MDG 7 for access to improved sanitation resulted in improved public health benefits and other benefits to the extent of 9 USD. Investment in South Africa by the government has led to an increase in the percentage of South African households with access to improved sanitation facilities. In 2015 , this parameter ranged from 71.0 to $93.6 \%$ of households as a function of the household income (Stats SA, 2016b, Figure 7.16, pp. 78). Investment and implementation of strategies to improve the population's access to improved drinking water and sanitation have contributed to a drop in the number of cases of diarrhoea among children under the age of 5 from 168.1 per 1000 children in 2000 to 90.3 per 1000 children in 2012 (HST, 2017).

However, despite all of these improvements in WASH situation in the country, challenges still seem to persist and at least some of the NDP goals remain out of reach (HST, 2017). The percentage of South African households who experienced pollution in the supplied drinking water ranged from 9.4 to $21.4 \%$ of all households in 2015 


\section{Acta Educationis Generalis \\ volume 8, 2018, issue 1}

(Statistics Stats SA, 2016b, Figure 6.43, pp. 64). In the same year, up to $87.3 \%$ of households in South Africa used an improved sanitation facility outside of their yard/dwelling (Stats SA, 2016b, Figure 7.22, pp. 83). This indicates that problems with the drinking water supply in South Africa remain or the population perceives that they do. At the same time, the sanitation facilities pose a problem with privacy during use and are in danger in falling into disrepair in public places (Hoossein et al., 2016).

These are problems that will contribute to the types of public health challenges that pharmacists in South Africa will face as part of practising their profession. As WASH is part of the practice of their future careers in South Africa, understanding of the context and underlying factors should therefore form an important component in the education of the B. Pharm. students. Water supply and sanitation, as well as the common lack of relevant service delivery, are not removed from the African context, but form a crucial part of it. Education of B. Pharm. students and the WASH context in South Africa must therefore be interlinked. These interlinks provide opportunities for curricular intervention, changes and transformation as desired currently by various stakeholders in the South African higher education sector. An example of a proposed paradigm for practical execution of such an intervention is outlined in the next section of this article.

\subsection{Proposed paradigm for transformation of the Bachelor of Pharmacy degree}

In the context of WASH and public health, one of the fundamental activities is the monitoring of microbial water quality which is to be carried out by the local government in South Africa (Luyt et al, 2012). Many local government authorities in South Africa face the problem of relative geographical isolation and financial challenges in the performance of regular compliance monitoring in their jurisdictions. Long distances between the water sampling sites and the laboratory result in the non-adherence with holding times for standard indicator microorganisms (Luyt et al., 2012). Nongovernmental stakeholders may step in to provide at least a partial solution to the problem (e.g. Tandlich et al., 2015). In this context, authors of the current paper have been extensively involved in the development of strategies for adaptation and low-cost solution to the problems in the WASH at the local government level in South Africa. This tool is the improved version of the H2S test kit (referred to as test kit in further text), which was originally developed in India and with the support of the WHO (Manja et al., 1982).

The test kit is available as a presence/absence or qualitative indication of faecal pollution in a drinking water supply (Mosley \& Sharp, 2005). A positive signal is detected by the production of black colour which can be visually read (Mosley \& Sharp, 2005). The medium is prepared by trained personnel in a laboratory in dehydrated form, and the individual sampling bottles are then distributed to inhabitants of households in the geographical areas where compliance monitoring should be performed. Laypersons can perform on-site tests and on a continuous basis by trained personnel with a microbiology background after a short introduction. The samples are stored at room temperature and must be shielded from direct sunlight. They are then visually checked for positive reaction, i.e. black colour development from the precipitation of iron sulphides, once every 12-24 hours for a total time of 72 hours (Manja et al., 1982). This provides an efficient visual test (Genthe \& Jagals, 2003). If the black colour develops within 72 hours, then there is likelihood of faecal contamination of the drinking water. If this does not occur, then no faecal contamination is present. 


\section{Acta Educationis Generalis \\ volume 8, 2018, issue 1}

The kits have been used in postgraduate teaching in the B. Pharm. degree in South Africa (Nhokodi et al., 2016). The learning process is a complex phenomenon, and there is no doubt that assessment can promote learning. By using a range of assessment tasks, it is also possible to cater for diversity. Assessment is a form of communication i.e. feedback to students on their learning and feedback to lecturers on their teaching (McAlpine, 2002). Assessment is the most significant tool that can be used to influence learning and appropriate changes can dramatically improve student performance (Gibbs, 1999). It should be viewed as a means to promote learning. Boud (1990) emphasized the link between assessment and learning when he wrote "learning is so driven by assessment that the form and nature of assessment often swamps the effect of any other aspect of the curriculum." Academics and educators at tertiary institutions spend considerable time on assessment. Despite the amount of time spent on assessment, many educators dislike the task and often do not do it properly (Snowman \& Biehler, 1997).

Lifelong learners actively assess their own learning; learn in both formal and informal situations; learn from their peers and teachers; integrate knowledge successfully and can successfully adapt to different circumstances. Assessment of learning is an important component of lifelong learning. Constructive alignment was a term first coined by Biggs (1999). "Constructive" refers to the notion that students construct meaning through relevant learning activities for themselves, and "alignment" refers to the teaching and learning environment provided by the educator (Biggs, 2005). Important components to consider are the curriculum, teaching methods, assessment procedures, student-teacher interaction and the institutional environment (Biggs, 1999). Educators should ideally design the curriculum so that the learning activities and assessment tasks are aligned with the learning outcomes that are intended for the particular course. Constructive alignment is more than criterion-reference assessment, which aligns assessment to the objectives (Biggs, 2005). Constructive alignment is a teaching system aimed at supporting learning, with the emphasis on the process rather than content (Reaburn et al., 2009).

The kit is relatively simple water-testing tool, where only qualitative nature of the output signal is read. However, it is an item which integrates various aspects of the B. Pharm. curriculum. Firstly, the role of packaging in the maintenance of integrity of the pharmaceutical product can easily be demonstrated. This comes from the fact that a dehydrated form of the incubation medium is stored inside a sterile urine jar. Secondly, the adherence to a simple quality-assurance protocol is necessary for the compliance monitoring using the kit. At the end of the day, the kit is however a scientific tool. Even though simple, the use and application of the kit will require the B. Pharm. students to integrate the knowledge from chemistry due to the redox nature of the process responsible for the positive signal, microbiology as the technique of the kit is sterile and based on the use/detection of microorganisms, pharmaceutical chemistry where packaging is taught, and students are introduced to it. Therefore, the kit should be introduced to the second-year students in the B. Pharm. curriculum, e.g. as the project at the interface of Quality of drugs module (Tandlich \& Moyo, 2016) and microbiology. The application to citizen science should provide context for the students to connect with the topic (Tandlich et al., 2015).

Disaster management approaches can be used to fast-track sanitation service delivery in South Africa (Hoossein et al, 2016). The leaflet developed in the workshop with Stenden South Africa students (see in Appendix I) provides a tool which can be used to monitor 


\section{Acta Educationis Generalis \\ volume 8, 2018, issue 1}

the status of ventilated improved pit latrines, a very common form of improved sanitation in South Africa, and to prevent compromised hygiene at the site of operation. This integrates research into disaster management and pharmacy into teaching and learning. The structure of the leaflet resembles the way that public health interventions should be run, i.e. they are based on the steps or delivered in phases which resemble the disaster management cycle. Incorporation of such activities into the B. Pharm. curriculum would integrate the principles of WASH, occupational safety and hygiene, similar to the study of Ižová (2011). This is based on the introduction and strengthening of the students' knowledge about the significance of faecal contamination of water, the significance of the respective monitoring in public health and also build on the everyday experience of the students from their lives.

In this way, the links between real-world problems and the pharmacy profession could be strengthened and the transformation of the B. Pharm. curriculum accomplished in part. Group work, which the students will be involved in during the assignment, will simulate the interaction with other stakeholders, e.g. other healthcare professionals, thus contributing to the achievement of cross-field outcomes of the B. Pharm. degree (SAQA, 2015-2018). In this way, the work situation will be simulated allowing B. Pharm. students to be introduced to what to expect in the practice of their professions. Coordination between the group members will require the pharmacists to learn and work effectively as members of a team and take the necessary action, similar to taking therapeutic decisions in the practice of pharmacy. Correct design of tools similar to that listed in Appendix I can be done on several topics. It is a task which the B. Pharm. students are familiar with from subjects such as Pharmacy Practice. They resemble a public health or health education communication tool such as health information leaflets. The design of leaflets, such as that listed in Appendix, will require B. Pharm. students to have prior knowledge as a foundation for the development of novel knowledge and is most likely to fall into the category of analyse and evaluate of Bloom's taxonomy (ISU, 1995-2018). Reflective practice involves thoughtfully considering one's own experiences in the application of knowledge to practice while being tutored by professionals in the discipline (Schon, 1996). The purpose of reflection is to learn through both positive and negative experiences, and to create a habit of examining experiences (Amulya, 2003-2011). Reflexivity, on the other hand, is an interactive process that requires an examination of priorities before a reaction (Newman \& Darling, 1998-2009). An important distinction between reflection and reflexivity is that reflection happens after completion of a task and is focussed in the future, while reflexivity incorporates introspection into each interaction and can have an immediate impact on teaching (Newman \& Darling, 1998-2009). Reflection has an effect on the development of reflexive practice. Reflexive lifelong learning often requires disruption or upheaval in the routines of life, such as a natural disaster, before they become part of social practice (Edwards et al., 2002). Therefore, design of leaflets and similar tools should form part of subjects in higher grades of the B. Pharm. degree, such as the final year elective module on Public Health and Disaster Management.

Validity and reliability define the overall quality of the assessment (McAlpine, 2002). For an assessment to be valid, it should accurately assess the outcome or measure what it is supposed to measure. Reliability is concerned with consistency and should be reproducible. The requirements for reliability over validity may vary for different assessment methods. Assessment can also be final or continuous. Final assessment is 


\section{Acta Educationis Generalis \\ volume 8, 2018, issue 1}

summative and happens only at the end of the course and is not used for formative purposes. Continuous assessment should take place throughout the course and allows students and lecturers to obtain feedback from the process, which can in turn be used to improve teaching and learning based on evidence gathered over the period of learning (McAlpine, 2002).

Summative assessment tasks include practical reports, tutorials, tests and examinations. An important role of assessment is to generate appropriate learning activities and to also provide prompt feedback that is taken notice of by the learner (Gibbs, 1999). Assessment is critical for the determination of whether the learning outcomes have been achieved. The reasons for assessment include: to provide a summary of learning, provide evidence of learning progress, to diagnose learners' strengths and weaknesses and to motivate further learning (Snowman \& Biehler, 1997). Assessment provides a summary of how well a student has met the objectives and summative assessment sums up a students' ability to perform a variety of tasks over a particular point in time (Snowman \& Biehler, 1997). Recently, assessment has appeared to obscure the pursuit of knowledge, but the pursuit of disciplinary knowledge should be at the centre of assessment (Shay, 2008).

Assessment can also be used to monitor progress of a particular student and formative assessment facilitates learning without assigning a grade (Snowman \& Biehler, 1997). Formative assessment is interactive feedback between student and educator that should enhance learning. This type of assessment provides feedback and requires that students reveal their shortcoming and is a long-term dynamic process to improve and react to the learning (Knight, 2001). This is associated with class discussions, tutorials and feedback on essays or practical assignments. This type of assessment could allow students to react to learning faster than summative assessment, which traditionally happens at the end of a course. It is focussed on the learning process.

\section{Conclusion}

The current article summarises some of topics and challenges that drive the current discourse, developmental and curriculum debate in higher education in South Africa. These challenges need to be addressed as matter of urgency. Student access and pass rates at tertiary institutions need to be improved and the curriculum needs to be transformed. Using a topic such as WASH might provide a way to address some of these challenges, and some strategies are proposed in this paper.

\section{Acknowledgments}

The authors would like to thank the first-year students at the School of Disaster Management of the Stenden South Africa for participating in the workshop for the development of the tool in Appendix.

\section{References}

Amulya, A. (2003-2011). What is reflective practice? (Reflection: the foundation of purposeful learning). Retrieved from https://www.communityscience.com/images/ file/What\%20is\%20Reflective\%20Practice.pdf

Badat, S. (2015). Deciphering the Meanings and Explaining the South African Higher Education Student Protests of 2015-16. Pax Academica, 1\&2, 71-106. 


\section{Acta Educationis Generalis \\ volume 8,2018 , issue 1}

Biggs, J. B. (2005). Aligning teaching for constructing learning. Higher Education Academy Discussion Paper. Retrieved from https://www.heacademy.ac.uk/ system/files/resources/id477_aligning_teaching_for_constructing_learning.pdf

Biggs, J., \& Tang, C. (1999). Teaching for quality learning at university (4 ${ }^{\text {th }}$ ed.). Buckingham, United Kingdom: Society for Research Into Higher Education and Open University Press.

Blankley, W., \& Booyens, I. (2010). Building a knowledge economy in South Africa (Commentary). South African Journal of Science, 106(11/12), Article \#373.

Boud, D. (1990). Assessment and the promotion of academic values. Studies in Higher Education, 15(1), 101-111.

BRICS 2017 China (BRICS2017.org, 2017). What is BRICS? Retrieved from www.brics2017.org/English/AboutBRICS/BRICS

Carnoy, M., Loyalka, P., \& Froumin, I. (2013). University expansion in BRIC countries and the global information economy. Change, July/August, 36-43. Retrieved from https://reap.fsi.stanford.edu/sites/default/files/University_Expansion_in_the_BRIC Countries.pdf

Chen, D. H. C., \& Dahlman, C. J. (2005). The knowledge economy, the KAM methodology and World Bank operations. Washington, DC, USA: The World Bank. Retrieved from siteresources.worldbank.org/KFDLP/Resources/KAM_Paper _WP.pdf

Council for Scientific and Industrial Research (CSIR-Health, 2018). Technology for better healthcare. Retrieved from https://csir.co.za/technology-better-healthcare

Delors, J., Al Mufti, I., Amagi, I., Carneiro, R., Chung, F., Geremek, B., Gorham, W., Kornhauser, A., Manley, M., Padron Quero, M., Savane, M.-A., Singh, K., Stavenhagen, R., Suhr, M. W., \& Nanzhao, Z. (1996). Learning: the treasure within. Education throughout life. International commission on education for the twenty-first century. Report to UNESCO (Paris, UNESCO). Paris, France: UNESCO Publishing. Retrieved from http://unesdoc.unesco.org/images/0010/ 001095/109590eo.pdf

Demirel, M. (2009). Lifelong learning and schools in the twenty-first century. Procedia Social and Behavioral Sciences, 1, 1709-1716.

Edwards, R., Ranson, S., \& Strain, M. (2002) Reflexivity: towards a theory of lifelong learning. International Journal of Lifelong Education, 21(6), 525-536.

G20-Turkish Presidency (G20, 2015). G20 Members. Retrieved from g20.org.tr/aboutg20/g20-members

Genthe, B., \& Jagals, P. (2003). Application of an $\mathrm{H}_{2} \mathrm{~S}$ Strip as a field test kit for microbial water quality assesmnet. Pretoria, South Africa: Water Research Commission. Retrieved from www.wrc.org.za/knowledge hub documents/research reports/1105-1-03.pdf

Gibbs, G. (1999). Using assessment strategically to change the way students learn. In S. Brown \& A. Glasner (Eds.), Assessment Matters in Higher Education. Buckingham: SRHE and Open University Press.

Hager, P. (2012). Concepts and Definitions of Lifelong Learning. Oxford Handbook of Lifelong Learning. Oxford, United Kingdom: Oxford University Press.

Health Systems Trust (HST, 2017). Health Indicators/Child Health/Child Health: Diarrhoea incidence under 5 years. Retrieved from http://www.hst.org.za/ healthindicators 


\section{Acta Educationis Generalis \\ volume 8,2018 , issue 1}

Heleta, S. (2016). Decolonisation of higher education: Dismantling epistemic violence and Eurocentrism in South Africa. Transformation in Higher Education, 1(1). Retrieved from https://www.thejournal.org.za/index.php/thejournal/article/ view/9 131

Hoossein, S., Tandlich, R., Whittington-Jones, K., Laubscher, R. K., Madikizela, P., \& Zuma, B. M. (2016). Disaster Management policy options to address the sanitation challenges in South Africa. Journal of Environmental Health, 78(7), E1-E7.

Human Science Research Council (HSRC, 2018). What we do. Retrieved from http://www.hsrc.ac.za/en/about/what-we-do

Hužovičová, M., \& Jakúbek, P. (2014). The lifelong learning in the field of employment policy in Slovakia. Acta Technologica Dubnicae, 4(2), 27-35. doi: 10.1515/atd2015-0003

Iowa State University (ISU, 1995-2018). Revised Bloom's Taxonomy. Retrieved from http://www.celt.iastate.edu/teaching/effective-teaching-practices/revised-bloomstaxonomy

Ižová, K. (2011). The Safety and hygiene at work in a school curriculum. Acta Technologica Dubnicae, 1(2), 61-65. doi: 10.1515/atd-2015-0047

Janeček, V. (2006). Military education and science. Science and Military, 1, 5-6.

Jůvová, A. (2017). The Guerrilla literacy learners' project: development of literacies through informal learning. Acta Technologica Dubnicae, 7(1), 83-92. doi: 10.1515/atd-2017-0005

Keeton, G. (2014). Inequality in South Africa. The Journal of the Helene Suzman Foundation, 74(November), 26-31.

Knight, P. (2001). A briefing on key concepts: Formative and summative, criterion and norm-referenced assessment. Assessment Series Learning and Teaching Support Network [LTSN] Generic Centre.

Luescher, T., Loader, L., \& Mugume, T. (2017). \#FeesMustFall: An Internet-Age Student Movement in South Africa and the Case of the University of the Free State. South African Journal of Political Studies, 44(2), 231-245.

Luyt, C. D., Tandlich, R., Muller, W. J., \& Wilhelmi, B. S. (2012). Microbial monitoring of surface water in South Africa. International Journal of Environmental Research and Public Health, 9(8), 2669-2693.

Manja, K. S., Maurya, M. S., \& Rao, K. M. (1982). A simple field test for the detection of faecal pollution in drinking water. Bulletin World Health Organisation, 60, 797 801.

McAlpine, M. (2002). Principles of assessment. Robert Clark Centre for Technological Education, University of Glasgow. Edited by CAA Centre, University of Luton. Bluepaper 1. Retrieved from http://caacentre.lboro.ac.uk/dldocs/Bluepaper1.pdf

Mosley, L. M., \& Sharp, D. S. (2005). The hydrogen sulphide paper strip test. SOPAC Technical Report 373.

National Planning Commission (NPC, 2013). National Development Plan 2030: Our future - make it work. Pretoria, South Africa: National Planning Commission, Presidency of the Republic of South Africa/Sherino Printers.

National Research Foundation of South Africa (NRF, 2018). Mandate. Retrieved from http://www.nrf.ac.za/about-nrf/mandate

Newman, J., \& Darling, I. (1998-2009). Educating as Inquiry: teaching as critical reflection reflective practitioner paper \#8. Action evaluation and action theory: an 


\section{Acta Educationis Generalis \\ volume 8,2018 , issue 1}

assessment of the process and its connection to conflict resolution. Retrieved from http://www.lupinworks.com/ar/Schon/Paper6.html

News24.com (2017). Student fee protests flare up at three universities. Retrieved from https://www.news24.com/SouthAfrica/News/student-fee-protests-flare-up-at-threeuniversities-20171023

Nhokodi, T., Nqowana, T., Collings, D., Tandlich, R., \& Köhly, N. (2016). Civic engagement and environmental sustainability in teaching and learning at a higher education institution in South Africa. Acta Technologica Dubnicae, 6(3), 66-82. doi: 10.1515/atd-2016-0020

Organisation for Economic Cooperation and Development (OECD, 2008-2017). Tertiary education for the knowledge society: pointers for policy development. Retrieved from https://www.oecd.org/education/skills-beyond-school/44007619.pdf and https://www.oecd.org/education/skills-beyond-school/47698479.pdf

Organisation for Economic Cooperation and Development (OECD, 2015). Education indicators in focus. Retrieved from http://data.oecd.org/eduatt/population-withtertiary-education.htm

Schon, D. A. (1996). Educating the reflective practitioner: Toward a new design for teaching and learning in the professions. San Francisco: Jossey-Bass, Inc.

Shay, S. (2008). Beyond social constructivist perspectives on assessment: the centering of knowledge. Learning and Teaching in Higher Education, 13(5), 595-605.

Snowman, J., \& Biehler, R. (1997). Psychology applied to teaching (8e - extracts). Geneva, IL, USA. Houghton Mifflin Harcourt Co. Retrieved from http://college.cengage.com/education/pbl/tc/assess.html\#4

South African National Department of the Health (SADOH, 2015). National Health Insurance for South Africa: Towards universal health coverage. Pretoria, South Africa: South African National Department of Health.

South African Pharmacy Council (SAPC, 2017a). Education. Retrieved from http://www.pharmcouncil.co.za/B_Edu_AccOfCourses.asp

South African Pharmacy Council (SAPC, 2017b). Registrations. Retrieved from http://www.pharmcouncil.co.za/B_Regs4_Overview.asp

South African Pharmacy Council (SAPC, 2017c). Accreditation of Courses. Retrieved from https://www.pharmcouncil.co.za/B_Edu_AccOfCourses.asp

South African Department of Science and Technology (DST, 2018). Overview. Retrieved from https://nationalgovernment.co.za/units/view/36/DepartmentScience-and-Technology-DST

South African Qualifications Authority (SAQA, 2014). South African Qualifications Authority Act no. 58 of 1995. Retrieved from http://www.saqa.org.za/show.php? $\mathrm{id}=5469$

South African Qualifications Authority (SAQA, 2015-2018). Retrieved from http://regqs.saqa.org.za/viewQualification.php?id=65130

South African Government (1997). Water Services Act no. 108 of 1997. Retrieved from www.dwa.gov.za/IO/Docs/a108-97.pdf

Statistics South Africa (Stats SA, 2016a). Mid-year population estimates 2016. Pretoria, South Africa: Statistics South Africa. Retrieved from http://www.statssa.gov.za/ ?page_id=1854\&PPN=P0302\&SCH=6688

Statistics South Africa (Stats SA, 2016b). General Household Survey (GHS) Series Volume VIII: Water and sanitation (In-depth analysis of the GHS 2002-2015 and 


\section{Acta Educationis Generalis \\ volume 8,2018 , issue 1}

CS 2016). Report No. 03-18-07 (2002-2015). Pretoria, South Africa: Statistics South Africa.

Statistics South Africa (Stats SA, 2017a). Education Series Volume III. Educational Enrolment and Achievement, 2016 (Report No. 92-01-03). Pretoria, South Africa: Statistics South Africa. Available at: www.statssa.gov.za/publications/Report\% 2092-01-03/Report\%2092-01-032016.pdf

Statistics South Africa (Stats SA, 2017b). General Household survey 2016 (Statistical release P0318). Pretoria, South Africa: Statistics South Africa. Retrieved from http://www.statssa.gov.za/?page_id=1854\&PPN=P0318

Steffens, K. (2015). Competences, learning theories and MOOCs: recent developments in lifelong learning. European Journal of Education, 50(1), 41-59.

Talati, J. J. (2014). Lifelong learning: established concepts and evolving values. Arab Journal of Urology, 12(1), 86-95.

Tandlich, R., Beukes, D. R., Naidoo, M. J., \& Tandlichová, E. (2013). Developing a pharmaceutical biotechnology course at a South African University. Published in the peer-reviewed proceedings from $5^{\text {th }}$ International Scientific and Expert Conference of the International TEAM Society, held in Prešov from $4^{\text {th }}$ until $6^{\text {th }}$ November 2013, 104-107.

Tandlich, R., Luyt, C. D., Irwin, B., Thinyane, H., \& Köhly, N. (2015). Nongovernmental information sources about microbial drinking water quality in South Africa. Forest, Marine and Ocean Ecosystems, Volume 2: ecology, economics, education and legislation conference proceedings - ecology and environmental protection environmental legislation, multilateral relations and funding opportunities (pp. 761-768). Published in the peer-reviewed conference proceedings from the 15th SGEM GeoConference on Water Resources from 18th until 24th June 2015. Albena, Bulgaria, published by STEF92 technology.

Tandlich, R., \& Moyo, F. (2016). Instruction of Pharmaceutical Chemistry to the second-year students at a South African University. Published in the peer-reviewed proceedings from the $7^{\text {th }}$ MAC conference held in Prague, Czech Republic from $27^{\text {th }}$ until $29^{\text {th }}$ May 2016, 110-129.

Technology Innovation Agency of South Africa (TIA, 2008-2018). Strategic roles. Retrieved from http://www.tia.org.za/strategic-roles

The South African (2018). Cape Town water restrictions: Residents now told to use just 50 litres a day. Retrieved from https://www.thesouthafrican.com/cape-town-waterrestrictions-501-a-day/

United Nations Human Development Index (UNHDI, 2016). Table 2: Trends in the Human Development Index, 1990-2014. Retrieved from http://hdr.undp.org/en/ composite/trends

United Nations (UN, 2014). Water scarcity. Retrieved from http://www.un.org/waterforlifedecade/scarcity.shtml

Vadra, R. (2017). Knowledge economy in BRICS: a case of South Africa. Journal of Knowledge Economy, 8, 1229-1240.

van Broekhuizen, H., van der Berg, S., \& Hofmeyr, H. (2016). Higher Education Access and Outcomes for the 2008 National Matric Cohort. Stellenbosch economic working papers, WP16/2016. Stellenbosch, South Africa: Department of Economics, University of Stellenbosch. Retrieved from https://www.ekon.sun.ac.za/wpapers/2016/wp162016 


\section{Acta Educationis Generalis \\ volume 8,2018 , issue 1}

Visser, J., \& Berg, D. (1999). Learning without frontiers: building integrated responses to diverse learning needs. Educational Technology Research and Development, 47(3), 101-114.

Water research Commission of South Africa (WRC, 2016). Technical Brief: Investigating the sustainability of desalination and water reuse. Retrieved from http://www.wrc.org.za/Pages/DisplayItem.aspx?ItemID=11591\&FromURL=\%2fPa ges $\% 2 \mathrm{fKH} \_$AdvancedSearch.aspx $\% 3 \mathrm{fdt} \% 3 \mathrm{~d} \% 26 \mathrm{~ms} \% 3 \mathrm{~d} \% 26 \mathrm{~d} \% 3 \mathrm{dInvestigating+t}$ he+sustainability+of+desalination+and+water+reuse $\% 26$ start $\% 3 \mathrm{~d} 1$

Water Research Commission of South Africa (WRC, 2018). Mandate. Retrieved from http://www.wrc.org.za/Pages/AboutUs.aspx

World Bank (WB, 2016). Life expectancy at birth, total (years). Retrieved from http://data.worldbank.org/indicator/SP.DYN.LE00.IN

World Bank (WB, 2017a). Gini index (World Bank Estimate). Retrieved from http://data.worldbank.org/indicator/SI.POV.GINI

World Bank. (WB, 2017b). Renewable internal freshwater resources per capita (cubic meters). Retrieved from http://data.worldbank.org/indicator/ER.H2O.INTR.PC? locations $=\mathrm{ZA}$

World Bank. (WB, 2017c). Average precipitation in depth (mm per year). Retrieved from https://data.worldbank.org/indicator/AG.LND.PRCP.MM

World Health Organisation (WHO, 2011). The Abuja Declaration: ten years on. Retrieved from www.who.int/healthsystems/publications/abuja_declaration/en/

World Health Organisation (WHO, 2016). WHO country cooperation strategy 20162020: South Africa. Brazzaville, Republic of Congo: WHO Regional Office for Africa. Retrieved from http://apps.who.int/iris/handle/10665/255007

\section{Appendix - Sanitation Infrastructure Assessment Tool}

\section{Disaster Management Aspects of Sanitation}

This pamphlet seeks to inform you as disaster management professionals about the possible disaster management risks from inadequately working sanitation infrastructure and the role of sanitation in disasters in general. It is designed to provide guidance on actions to be undertaken during the individual stages of the disaster management cycle and in term of sanitation.

1. Disaster Health Risks and Hazards Register from Sanitation

- Hygiene is also essential in the prevention of disease outbreaks spread.

- $\quad$ Provision of safe drinking water and improved sanitation are essential to hygiene.

- Provision of sanitation and safe drinking water in the disaster areas are among the first recovery operations that need to be undertaken.

- Improved sanitation in South Africa is provided in one of two forms, i.e. waterborne toilets or the ventilated improved pit latrines (VIPs).

- VIPs have a more significant role in disaster management in South Africa as they form the minimum standard of sanitation according to the South African government and legislation.

- VIPs must be maintained by your local municipality, e.g. the municipal officials are responsible for emptying and checking of physical integrity of the VIPs. 


\section{Acta Educationis Generalis \\ volume 8, 2018, issue 1}

- A VIP that is not maintained, then it is a source of disaster risk from injuries as people can fall into the pit.

- Incorrect construction of the toilet can lead to side-walls of the toilet leaking the stored material out of the VIP.

- Use of improperly functioning communal toilet can lead to the spread of infectious diseases, i.e. cholera and typhoid.

- If water leaks from a sanitation facility pools of water form provides breeding ground for mosquito growth.

- If malaria is endemic in a given area, then this could cause an outbreak.

- Pooling can lead to exposure of children and other immune-compromised patients to faecal material, i.e. leading to transmission of waterborne diseases.

- These can be prevented dispensing bleach and other water purification items to the disaster-affected population. This is even more important in areas with high degree of immune-compromised character, e.g. HIV-prevalence is high in townships.

- If a member of the community is HIV-positive, then a properly working toilet is a must!

- Special focus must be put on the privacy of the community members.

- $\quad$ Privacy is best protected by consulting the community before any disaster about the preferred type of sanitation.

- Increased requirements for sanitation must be assessed based on the data on HIV prevalence in the (disaster) area. Respective data can be obtained from the district or sub-district office of the provincial department of health.

- Hygiene is a pre-requisite of good maternal health and eliminates the spread of bladder infections among women.

- Adequate sanitation is also critical to protection of physical safety of women. Therefore, special attention should be paid to it in disaster management consideration by you and your staff.

- Sanitation and maternal health are of critical importance in rural areas of South Africa where they have direct links to the households' vulnerability.

\section{Response}

- Maintain an active taskforce of relevant stakeholders and perform an ongoing sanitation facilities audit to establish a baseline reference or pre-disaster starting point.

- Gather as much information as possible on the ground once a sanitation-related disaster has taken place.

- In collaboration with as many stakeholders as possible as collect the following information:

a) What type of damage took place?

b) What is the extent of injuries?

c) What are the fatalities in any?

d) How many people are affected and without sanitation as a result of the disaster?

e) How can local stakeholders that are members of the relevant disaster management advisory forum help in providing emergency facilities? 


\section{Acta Educationis Generalis \\ volume 8, 2018, issue 1}

- You as local disaster management professionals should, in collaboration with local district or sub-district office of the provincial department of health and NGOs, take lead in putting together a register of human casualties and infrastructure damage.

- You must also coordinate the provision of emergency water supply and sanitation for the affected communities and areas.

- You must contain any spills of faecal material using technologies such as Floodsax.

- Cholera and waterborne diseases: contact emergency medical personnel and Provincial Department of Health for assistance.

- Take lead in putting place quarantine if necessary.

- Using the municipal resources or the resources of the volunteer unit or the local disaster management advisory forums to maintain the most efficient disaster management operations.

\section{Mitigation}

- Using local forums, such as the local disaster management advisory forums, women's groups, NGOs and community meeting awareness campaigns should be run in areas prone to sanitation-related disasters.

- These activities should educate people on how improved sanitation is properly built and what are the signs of dysfunction and you as the local disaster management official must take a lead in them.

- Take time to translate as many awareness materials as possible into local languages, e.g. isiXhosa, isiZulu and isiNdebele.

- When making presentations, recruit a staff member from your office who speak local languages e.g. isiXhosa, isiZulu and isiNdebele to assist with awareness workshops.

- Maintenance and the responsibilities of the local government should be explained to the population in detail.

- This is meant to empower the community and manage public risks from sanitationrelated disasters.

- Awareness campaigns have no punitive aims and this must be understood by all stakeholders.

- If financial resources are limited, then the local disaster management staff should pay special attention to establishing volunteer units to fill the skill's gap.

- Use your authority and local contractors to fence of hazards and sources of risk. Platforms for this include the National Environmental Management Act and the Disaster Management Act.

- Hold regular meeting with the water and sanitation department personnel from your area of jurisdiction about the status of sanitation facilities and the challenges at hand.

4. Preparedness

- Educating people on how to deal with situations, infrastructure and how to build the pit latrines. The importance of using the right equipment.

- Perform regular check on the emergency equipment, e.g. pumps, and maintain technical workshop with your staff on their proper operation. 


\section{Acta Educationis Generalis \\ volume 8, 2018, issue 1}

- Use freely available resources, e.g. the website of the Water Research Commission and the South African National Department of Water and Sanitation, to keep abreast about the latest local research into sanitation.

- Use this information to procure the best-available technique equipment in the areas of water and sanitation provision under disaster conditions.

- Maintain a database of skills and contact details of the local non-governmental stakeholders to assist in disaster recovery.

5. Disaster Recovery

- Rebuilding of improved sanitation facilities with properly trained and certified contractors to eliminate future problems.

- Medical attention should be provided to any community members showing symptoms of sanitation-related diseases.

- The follow-up visits to affects communities must be regular and follow the principles of a two-way communication, i.e. you get the information needed to eliminate disaster risk and the communities get the feeling of being consulted and included.

- Approach to recovery and follow-up visits will have a positive impact on the relationship between the disaster management professionals, i.e. YOURSELF, and the community members during future disasters.

- You as local disaster management professionals should help facilitate counselling for the community members who might be affected by the loss of privacy while using sanitation facilities.

- Counselling and other necessary public health services must be provided in coordination with the local district or sub-district office of the provincial department of health and NGOs.

6. Members of the disaster management advisory forums and potential volunteers

- Hospital and clinics;

- $\quad$ Emergency personnel such as police and fire department;

- Municipality involved (volunteers);

- Professionals involved in hygiene;

- Councillors;

- Farmers;

- Local Business (for relief).

Communication must be a two-way exchange of information and must be regular, e.g. monthly meeting in churches, schools or community centres. Community members must feel and be included in all decisions about sanitation and development of new sanitation infrastructure in their communities. The involvement of traditional leaders and community organisation representatives must be implemented as much as possible in the sanitation service provision. 


\section{Acta Educationis Generalis \\ volume 8,2018 , issue 1}

\section{Examples of visual VIP fault detection}

a) Blocked pit extraction pipe as the arrow points in the picture below extraction of the toilet contents is impossible and public health compromised as the continued use of the facility by the occupants is impossible.

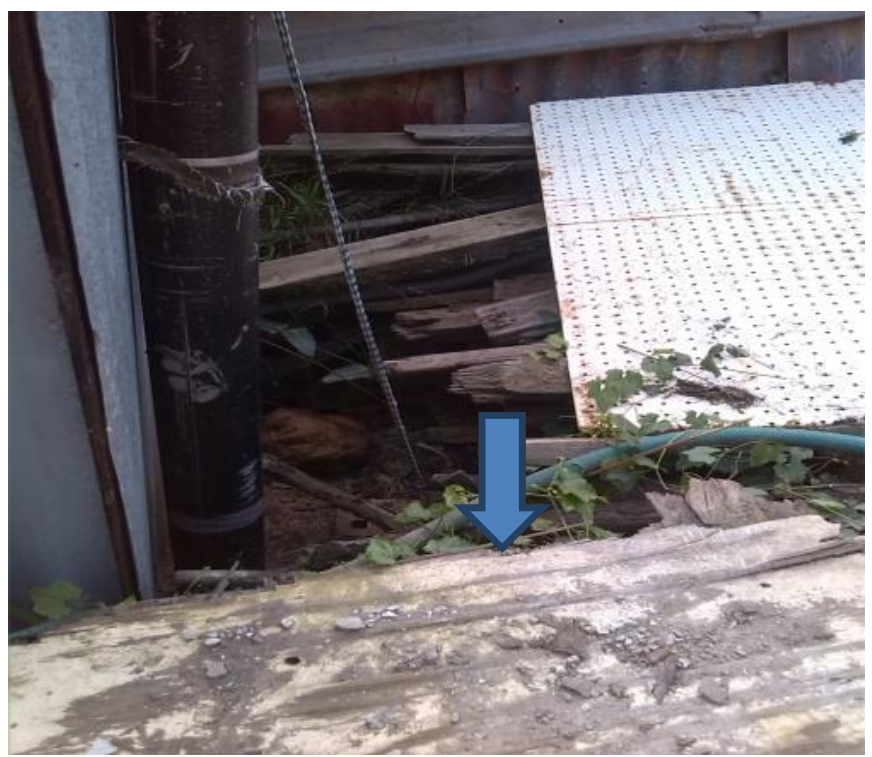

b) Ingress of soil into the VIP pit, i.e. soil particles are visible in the VIP pit point to the compromised side walls of the toilet facility and possible collapse.

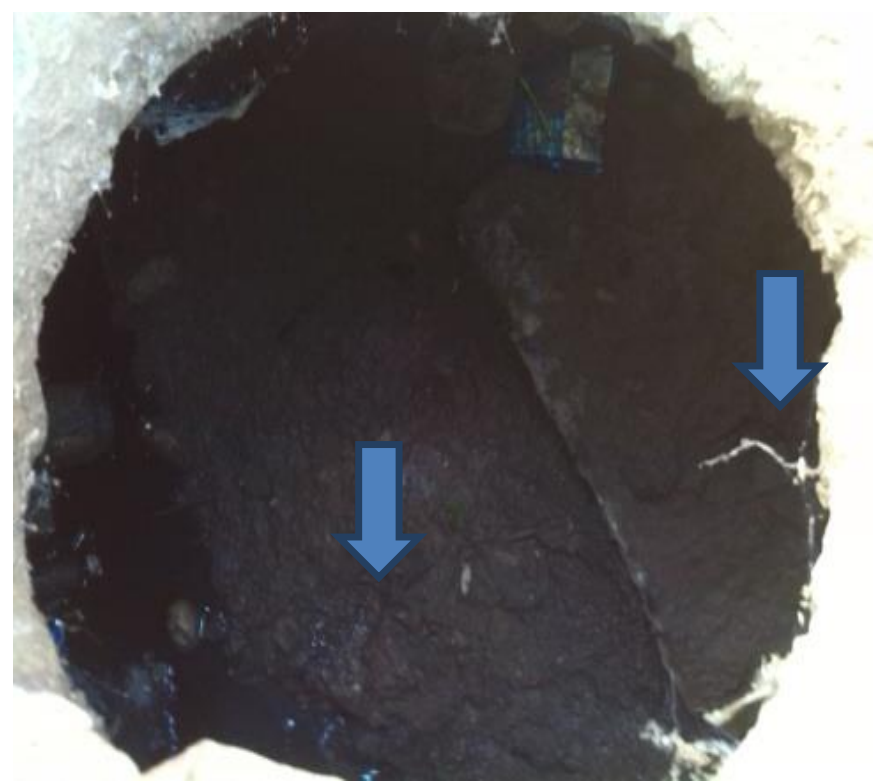




\section{Acta Educationis Generalis}

volume 8,2018 , issue 1

c) Signs of soil erosion and the potential for the total collapse of the VIP.

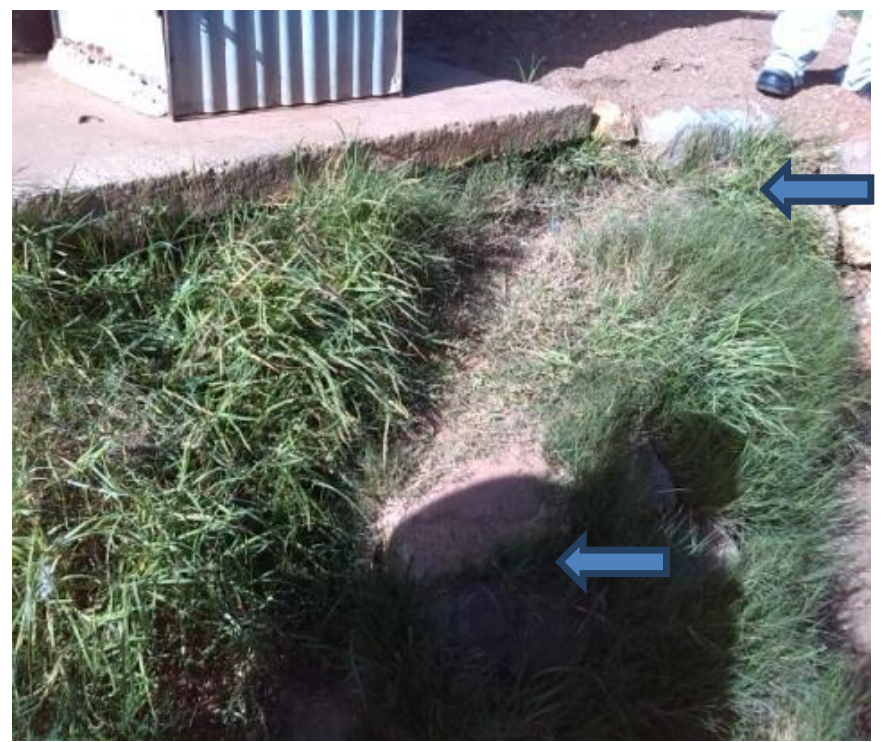

